\title{
Abnormal Pap smear frequency and comparison of repeat cytological follow-up with colposcopy during patient management: the importance of pathologist's guidance in the management
}

\author{
Drol Arslan, ${ }^{1}$ (i) Fulya Gokdagli, ${ }^{1}$ (i) Halenur Bozdag, ${ }^{1}$ (i) Dogan Vatansever, ${ }^{2}$ (i) Michael Karsy ${ }^{3}$ \\ 1'Department of Obstetric and Gynecology, Medeniyet University Goztepe Training and Research Hospital, Istanbul, Turkey \\ 2Department of Obstetric and Gynecology, Kartal Training and Research Hospital, Istanbul, Turkey \\ ${ }^{3}$ Department of Pathology, New York Medical College, Valhalla, New York, NY, USA
}

\begin{abstract}
OBJECTIVE: Cervical cancer contributes to a significant global health burden with room for improvement of primary prevention methods. This study aimed to determine the prevalence of Turkish women with abnormal cytology and their management by comparing results from repeat cytological analysis with close follow-up and colposcopy.

METHODS: A retrospective evaluation of 8738 women who underwent Pap smears at a single institution during 2011 was performed. Either repeat cytological analysis or colposcopic biopsy was used for follow-up evaluation of women who had abnormal index cytology.

RESULTS: From the 8670 women, 8259 of had normal cytology results (95.3\%) and 411 women had abnormal cytology (4.7\%) in the index Pap smear. The frequency of initial abnormal cytology was $65 \%(n=267), 27 \%(n=111), 3.4 \%(n=14)$, $2.4 \%(n=10), 1.9 \%(n=8)$, and $0.3 \%(n=1)$ for atypical squamous cell of undetermined significance (ASCUS), low-grade squamous intraepithelial lesion (LSIL), ASC cannot exclude high-grade intraepithelial lesion (ASC-H), high-grade SIL (HSIL), atypical glandular cells (AGC), and invasive cancer, respectively. Of the 267 women with initial ASCUS, 108 (40.4\%) underwent repeat cytology analysis, 84 (31.5\%) underwent colposcopic biopsy, and 75 (28.1\%) were lost to follow-up. On histopathology, $8.3 \%(n=7)$ of patients had cervical intraepithelial neoplasm 2 (CIN2) on colposcopy. Of 60 women with LSIL that underwent colposcopic biopsy, $13.3 \%(n=8)$ had CIN2/3.
\end{abstract}

CONCLUSION: The results of the study suggest that routine cytological follow-up may be an appropriate method in the management of ASCUS instead of immediate colposcopy while immediate colposcopy cannot place repeat cytology for LSIL in developing countries.

Keywords: Atypical squamous cell of undetermined significance; colposcopy; cytology; low-grade squamous intraepithelial lesion; Pap smear.

Cite this article as: Arslan E, Gokdagli F, Bozdag H, Vatansever D, Karsy M. Abnormal Pap smear frequency and comparison of repeat cytological follow-up with colposcopy during patient management: the importance of pathologist's guidance in the management. North Clin Istanb 2019;6(1):69-74.

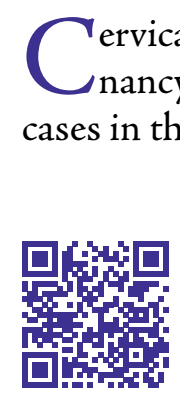

2012. Regardless, most of the cervical cancer cases arise from developing countries mainly due to the limited use of cytological screening tests [1].

Received: August 05, 2017 Accepted: January 22, 2018 Online: August 14, 2018

Correspondence: Dr. Erol ARSLAN. Medeniyet Universitesi, Goztepe Egitim ve Arastirma Hastanesi, Kadin Hastaliklari ve Dogum Klinigi, Istanbul, Turkey.

Tel: +902122134400 - 3230 e-mail: dr_erolarslan@hotmail.com

(c) Copyright 2019 by Istanbul Provincial Directorate of Health - Available online at www.northclinist.com 
MORTH CLIn ISTARB

While primary human papillomavirus (HPV) screening is being popular especially in developed countries, the papanicolaou, or Pap smear test is still the most widely used screening test for cervical cancer worldwide. By that time, it allows early diagnosis and treatment of cervical premalignant lesions, which may advance to cervical cancer without treatment. However, it has to keep in mind that this test is not perfect and has a false positive rate up to $50 \%$, in cervical cancer cases. While the prevalence of abnormal cytology increases with screening programs, the incidence and mortality rate of cervical cancer also reduces dramatically in countries with such analysis $[2,3]$. Although the specificity of the Pap smear test was found as high as $81.8 \%$ by previous studies, its sensitivity is said to be low as $57 \%$ [4]. It was shown that use of a single smear was only able to diagnose cervical intraepithelial neoplasm (CIN) of any grade in $51 \%$ of cases and that diagnostic efficacy increased with high-grade lesions [5].

Atypical squamous cells of undetermined significance (ASCUS) are the most commonly seen cervical abnormality in cytological results following by low-grade squamous intraepithelial lesion (LSIL) $[6,7]$. The American Society for Colposcopy and Cervical Pathology, offers three possible ways for management of ASCUS: (1) Follow-up with cytology, (2) HPV testing, or (3) colposcopy. Different countries choose distinct pathways depending on their resources, social factors, and health-care system features [8]. Furthermore, at the time these guidelines were reported, HPV testing was not frequently used in Turkey or many other countries, and most patients were managed by either cytological follow-up or colposcopy. Colposcopy is a very good screening and diagnostic tool, which allows the ability to diagnose and manage premalignant lesions, can be performed outpatient in a short span of time, and is well tolerated by patients. It is still considered the gold standard for the evaluation of patients with cervical lesions and abnormal smear results [5]. Nevertheless, because it is an invasive method and more costly intervention than the cytological follow-up, the use of colposcopy after a single ASCUS result is still a dilemma for developing countries.

We aimed to determine the rate of ASCUS and other abnormal Pap smear results of women undergoing gynecological evaluation in an outpatient clinic during a 1 year time period, and compare the colposcopy results and cytological follow-up after newly diagnosed ASCUS and LSIL.

\section{MATERIALS AND METHODS}

\section{Study population}

After Hospital Research Ethics Committee approval, a retrospective chart and pathological review of 8738 women who applied or were referred for Pap smear tests at the Department of Obstetrics and Gynecology in Goztepe Research and Training Hospital from January 1, 2011, to January 1, 2012, were evaluated. All patients were assessed in an outpatient setting, and the age range was from 18 to 60 years and the mean age of patients' was $42.4 \pm 9.6$. Subjects who were pregnant, immunosuppressed or had previously treated cervical diseases, total hysterectomies or previous cytological abnormalities were excluded. For women who had more than one Pap smear during this time for different reasons, only their first smear was included. Patients who had cytological abnormalities were informed in detail and possible management methods followed by either cytological follow-up by repeat Pap smear or histological diagnoses by colposcopy. Women who refused either approach or sought care at other hospitals were excluded from the second part of this study.

\section{Cervical cytology}

The conventional Pap smear method was used for cervical cytology as previously described [9]. Briefly, samples were fixed in $95 \%$ alcohol at the time of acquisition and analyzed as smears on microscope slides according to the Bethesda 2001 system by a pathologist [9].

\section{Colposcopy}

Colposcopy with biopsy was performed in patients with cytological abnormalities of at least ASCUS grade or higher, who consented to the procedure. Decisions for pursuing colposcopy were at the discretion of the patient's treating physician. After high magnification visualization of the cervix for probable lesion was performed, acetic acid at 3-5\% followed by Lugol's solution (Schiller's test) was applied. Biopsies were obtained from lesions, and if there was no visible lesion, samples from 4 quadrants ( 3 , 6,9 , and 12 o'clock directions) were obtained. Endocervical curettage was implemented in all patients. All the samples were sent to the pathology department and examined by a pathologist.

\section{Statistical methods}

The data were entered into a password-protected database. Continuous variables were analyzed as means and stan- 
dard deviations as well as by t-test. Discrete variables were analyzed by the Chi-squared test. The Statistical Package for the Social Sciences (SPSS) software version 20.0 (SPSS, Armonk, NY, USA) was used for analyzing data.

\section{RESULTS}

A total of $68 / 8738(0.8 \%)$ women had insufficient material for evaluation, and 8259 of the remaining 8670 (95.3\%) showed normal cytology. The descriptive results of the remaining $411 / 8670$ (4.7\%) cases showing abnormal cytology and the distribution of patients, those who did not undergo follow-up at our institution $(n=109$, $27 \%)$, are shown in Table 1.

Of the 192 women evaluated for ASCUS, 108/192 $(56.3 \%)$ underwent a repeat smear within 6 months, while $84 / 192(43.7 \%)$ underwent colposcopy with biopsy $(\mathrm{p}=0.02)$. Among 192 ASCUS patients, 61 of them had a pathological comment that the diagnosis would be due infection/inflammation and/or senile atrophy and needed a second cytology assessment after treatment of vaginitis. In this group, $88.5 \%(n=54)$ of women had normal cytology, 9.8\% $(n=6)$ had ASCUS again, and only one patient had LSIL after treatment. Regarding this case of LSIL, it was noted that the ASCUS diagnosis may be mostly due to reactive changes secondary to infection, but the sign of koilocytosis due to HPV infection still could not be ruled out.

From the remaining 131 patients with ASCUS, 47/131 (35.9\%) underwent a repeat smear within 6 months, while $84 / 131$ (64.1\%) underwent colposcopy with biopsy $(p<0.001)$. In the management of LSIL, 60 women underwent colposcopy, while 21 women with LSIL declined colposcopy and preferred cytological follow-up and so Pap smear was performed those within 6 months. The subgroup analysis of those patients with ASCUS and LSIL and the results of cytopathology were shown in Table 2. In LSIL patients, the rate of total abnormal pathology and CIN2-3/ASCH-HSIL was not significantly different between colposcopy and repeat cytology groups (34/60 vs. 5/21, $\mathrm{p}=0.11$ and $8 / 60$ vs. $1 / 21, p=0.3)$, while the rate of CIN1/LSIL and/or CIN1/ASCUS-LSIL was significantly higher in colposcopy group $(26 / 60$ vs. $4 / 21, \mathrm{p}<0.05)$.

Elsewhere, a total of 10 patients with index ASC-H and 9 with index HSIL patients underwent colposcopy on follow-up. The biopsy results showed 3/19 (15.8\%) with normal or chronic cervicitis, $3 / 19$ (15.8\%) with CIN1, and 13/19 (68.4\%) with CIN2/3.

\section{DISCUSSION}

Cancer of the uterine cervix is the fourth leading source of cancer-related death in women in the worldwide and the second most common cause of cancer and cancer deaths following breast cancer in developing countries $[1,10]$. One of the key differences in cervical cancer mortality between different countries involves the screening programs available within distinct health-care systems. Cervical cancer has a well-defined pre-invasive stage with a long incubation until intraepithelial neoplasia development and subsequent invasive neoplasm. Effective screening has been shown to decrease the rate of cervical neoplasm progression by instigating earlier treatment,

TABLE 1. Distribution of abnormal index Pap-smear cytology

\begin{tabular}{lcccc} 
Diagnosis & $\begin{array}{c}\text { Number of patients } \\
\text { with specific cytology }\end{array}$ & $\begin{array}{c}\text { The rate of specific } \\
\text { cytology in all } \\
\text { abnormal cytology }\end{array}$ & $\begin{array}{c}\text { The rate of specific } \\
\text { cytology in all patients }\end{array}$ & $\begin{array}{c}\text { The number and rate of } \\
\text { patients that refused } \\
\text { further management }\end{array}$ \\
\hline ASCUS & 267 & $267 / 411(65 \%)$ & $267 / 8670(3.1 \%)$ & $75 / 267(28 \%)$ \\
ASC-H & 14 & $14 / 411(3.4 \%)$ & $14 / 8670(0.2 \%)$ & $3 / 14(21 \%)$ \\
LSIL & 111 & $111 / 411(27 \%)$ & $111 / 8670(1.3 \%)$ & $30 / 111(27 \%)$ \\
HSIL & 10 & $10 / 411(2.4 \%)$ & $10 / 8670(0.1 \%)$ & $1 / 10(10 \%)$ \\
AGC & 8 & $8 / 411(2.0 \%)$ & $8 / 8670(0.1 \%)$ & - \\
Invasive cancer & 1 & $1 / 411(0.2 \%)$ & $1 / 8670(0.01 \%)$ & - \\
\hline
\end{tabular}

ASCUS: Atypical squamous cell of undetermined significance; LSIL: Low-grade squamous intraepithelial lesion; ASC-H: Atypical squamous cells cannot exclude highgrade intraepithelial lesion; HSIL: High-grade intraepithelial lesion; AGC: Atypical glandular cells. 
TABLE2. Subgroup analysis of repeat cytology and colposcopy results

\begin{tabular}{|c|c|c|c|c|c|c|c|c|}
\hline \multirow[t]{3}{*}{ Repeat pathology typ } & \multicolumn{4}{|c|}{ ASCUS $(n=131)$} & \multicolumn{4}{|c|}{ LSIL } \\
\hline & \multicolumn{2}{|c|}{$\begin{array}{l}\text { Cytology } \\
(n=47)\end{array}$} & \multicolumn{2}{|c|}{$\begin{array}{l}\text { Colposcopy } \\
(n=84)\end{array}$} & \multicolumn{2}{|c|}{$\begin{array}{l}\text { Cytology } \\
(n=21)\end{array}$} & \multicolumn{2}{|c|}{$\begin{array}{l}\text { Colposcopy } \\
(n=60)\end{array}$} \\
\hline & $\mathrm{n}$ & $\%$ & $\mathrm{n}$ & $\%$ & $\mathrm{n}$ & $\%$ & $\mathrm{n}$ & $\%$ \\
\hline Normal/inflammation & 32 & 68.1 & 51 & 60.7 & 16 & 76.2 & 26 & 43.3 \\
\hline ASCUS & 6 & 12.8 & - & - & 2 & 9.5 & - & - \\
\hline LSIL & 7 & 14.9 & - & - & 2 & 9.5 & - & - \\
\hline ASC-H & 2 & 4.2 & - & - & 1 & 4.8 & - & - \\
\hline CIN1 & - & - & 26 & 31.0 & - & - & 26 & 43.3 \\
\hline CIN2/3 & - & - & 7 & 8.3 & - & - & 8 & 13.4 \\
\hline
\end{tabular}

ASCUS: Atypical squamous cell of undetermined significance; LSIL: Low-grade squamous intraepithelial lesion; ASC-H: Atypical squamous cells cannot exclude highgrade intraepithelial lesion; CIN: Cervical intraepitelial neoplasia.

especially in developed countries $[11,12]$. Although cervical cancer incidence decreases with screening programs, the rate of intraepithelial neoplasia rises and presents a challenge in managing patients with atypical screening results.

In this study, we aimed to summarize the distribution of abnormal cytology in a representative population of Turkish women as well as demonstrate the practical results of current management by a variety of follow-up methods. The rate of total abnormal cytology was $4.7 \%$ in our study in which is similar to the prior literature $[2,13]$. ASCUS and LSIL composed $92 \%$ of all pathological Pap smear results in our study. This finding is consistent with the literature in which showed that detection of ASCUS followed by LSIL was increasingly diagnosed after screening programs were implemented [2]. Interestingly, our ASCUS and LSIL rate was three and four times higher than a previous multicenter Turkish study (3.1\% vs. $1.07 \%$ for ASCUS and $1.3 \%$ vs. $0.3 \%$ for LSIL), in which our center was one of the participants [14]. Although there are three accepted methods in the management of ASCUS, including colposcopy, HPV testing, and cytological follow-up, [15] further evaluation is highly related to the availability of the tests, health-care system and the economical status of countries. While the increased rate of ASCUS detection after the screening, newer strategies with lower cost have also been explored [16]. In this manner, we separate the ASCUS patients into two groups based on pathological diagnosis. Depended on pathology, 61/192 (31.8\%)
ASCUS patients that underwent repeat cytology after having treatment for infection and/or atrophy and nearly $90 \%$ of them had normal cytology. In addition, only one patient showed LSIL in which the pathologist attributed the ASCUS diagnosis to infection but still could not eliminate the sign of koilocytosis due to HPV infection. In contrast, 9/47 (19.1\%) patients showed at least LSIL (7 LSIL and 2 ASC-H) in the second cytology group, which was significantly higher than detection in the index cytology analysis $(p<0.05)$. These findings show us the importance of the pathologist in the cytological diagnosis, but also as an active partner in the management of ASCUS by influencing further clinical management decisions at follow-up. Excluding the 61 patients with discrepant index and follow-up pathology, the remaining 131 ASCUS patients with repeat cytology or colposcopy did show difficulty in identifying whether the diagnosis could have arisen. The third method of management after abnormal index pathology, involving HPV testing, was not used in the management because it was not widely compassable in our country at that time. Despite that it has been used later in Turkey, it is still not available in a wide number of developing countries [8]. In addition, HPV testing was found to be more costly than direct colposcopy in such countries in contrast to developed countries like USA [8].

Use of repeat cytology for follow-up must be able to avoid missing higher grade CIN2/3 lesions. A CIN2 rate of $8.3 \%$ was seen in our study for the colposcopy group, which was similar to the other studies $[16,17]$. While 
Kabaca et al. [16] demonstrated a rate of invasive cancer as high as $1.95 \%$ during colposcopy after initial ASCUS determination, we did not find any invasive cancer or CIN3 in the ASCUS group. In this study, histopathologic examination of ASCUS patients revealed normal histology or chronic cervicitis in $60.7 \%(n=51 / 84)$ of patients while $31 \%(n=26 / 84)$ showed CIN1, 8.3\% $(n=7 / 84)$ of women had CIN2, and none had CIN3 or invasive cancer on biopsy. Despite the high CIN1 rate, it is well known that most of the CIN1 cases have a higher regression rate and only $1 \%$ of cases will progress to invasive cancer [5]. In addition, our study showed similar rates of pathologies in cytological follow-up group compared to colposcopy when the ASCUS patients that most thought to be due to infection by a pathologist, were excluded. Elsewhere, a recent study showed that repeat cytology in 4-6 months was 34\% less costly than immediate colposcopy in ASCUS management [18]. All these findings support the cytological follow-up in ASCUS patients in an effective way particularly in developing countries and especially if the pathologist has an active role in the management. As mentioned previously, $27 \%$ of patients did not have any follow-up procedure in our hospital, and while we assume they may have follow-up elsewhere, it is unclear. Therefore, it is crucial to inform patients aware of their screening results in a timely manner. Thus, it should be kept in mind women recommended for repeat cytology require close followup and the possibility of failure to follow-up should be considered during evaluation.

Our study evaluated the rate of LSIL and follow-up pathology types. The rate seen in this study $(1.3 \%)$ was similar to prior studies $[2,19]$. Despite this, our LSIL rate was much higher than a 2007 Turkish multicenter study which found that rate $0.3 \%$ [14]. This bigger difference may not be due to more effective screening but could also be due to an increasing prevalence of preinvasive lesions. This interpretation was supported by different studies $[2,20]$. Most patients $(n=60)$ in the LSIL group underwent colposcopy with biopsy, which is the preferred management of LSIL [6]. In contrast, 21 women refused to undergo colposcopy and underwent repeat cytology. They were informed about the importance of colposcopy in the management and potential false negativity of repeat cytology.

While our ASCUS and LSIL rates were similar with recent studies $[2,13]$ in the study by Stolnicu et al., the rate of ASC-H and HSIL was much higher than our study $(1.0 \%$ vs. $0.2 \%$ for ASC-H and $0.9 \%$ vs. $0.1 \%$ for
HSIL) [13]. This may be due to a variety of reasons including screening programs, HPV incidence, and/or sociocultural factors that affect the women in different countries. Although our CIN2-3 rate in LSIL group was similar to the $15.26 \%$ rate of a previous Turkish study [16], Pothisuwan et al. found CIN2-3 rate as high as $20 \%$ in 51 women with LSIL [20]. In this study, a normal histology rate of $20 \%$ was identified, which is slightly lower than ours. Despite our higher false positive rate for LSIL than other pathologies and considering that $57 \%$ of patients had at least CIN1 on colposcopy, follow-up of these patients with colposcopy may be the best method of management for LSIL.

Some limiting factors of our study include the small sample size and retrospective nature of the analysis. The relative portion of patients with atypical pathology after initial screening was small. However, we felt our sample population can represent the Turkish population since our center served a large population with different incomes, education, and sociocultural factors due to its location. In addition, nearly $27 \%$ of participants were lost to follow-up. This study was retrospective and based on opportunistic screening. Moreover, only a conventional cytological preparation was used at our institution despite the more common thin-prep method being developed in Turkey after this study. Elsewhere in the management of ASCUS, the role of HPV testing could not be predicted due to its narrow use at the time when the study took place. Despite these disadvantages, our study was the first study to separate and managed ASCUS patients due to pathologist's opinion, and so in this study, the role of the pathologist was taken into account beyond the initial diagnosis.

Conflict of Interest: The authors declare no conflict of interest.

Financial Disclosure: The authors declared that this study has received no financial support.

Authorship Contributions: Concept - E.A., F.G.; Design - E.A., F.G., H.B., M.K.; Supervision - H.B., M.K., D.V.; Data collection \&/or processing - E.A., F.G.; Analysis and/or interpretation - E.A., M.K., H.B., D.V.; Writing - E.A., M.K.; Critical review - H.B., D.V., F.G.

\section{REFERENCES}

1. GLOBOCAN 2012: Estimated Cancer Incidence, Mortality and Prevalence Worldwide in 2012. Available at: http://www.globocan.iarc. $\mathrm{fr} /$ Pages/fact_sheets_cancer.aspx.

2. Bassal R, Schejter E, Bachar R, Shapira H, Sandbank J, Supino Rosin L, et al. Cervical pap screening among Israeli women, 2005-2010. Arch Gynecol Obstet 2014;289:615-22. [CrossRef] 
3. Noller KL. Cervical cytology screening and evaluation. Obstet Gynecol 2005;106:391-7. [CrossRef]

4. Arbyn M, Buntinx F, Van Ranst M, Paraskevaidis E, Martin-Hirsch P, Dillner J, et al. Virologic versus cytologic triage of women with equivocal pap smears: A meta-analysis of the accuracy to detect high-grade intraepithelial neoplasia. J Natl Cancer Inst 2004;96:280-93. [CrossRef]

5. John OS, Joseph IS, Lisa MH, Barbara LH, Karen DB, Gary C. Willams Gynecology. 1st ed. Texas: Mc Graw Hill Medical; 2008. p. 617-45.

6. Garrett LA, McCann CK. Abnormal cytology in 2012: Management of atypical squamous cells, low-grade intraepithelial neoplasia, and highgrade intraepithelial neoplasia. Clin Obstet Gynecol 2013;56:25-34.

7. Sundström K, Lu D, Elfström KM, Wang J, Andrae B, Dillner J, et al. Follow-up of women with cervical cytological abnormalities showing atypical squamous cells of undetermined significance or low-grade squamous intraepithelial lesion: A nationwide cohort study. Am J Obstet Gynecol 2017;216:48.e1-15. [CrossRef]

8. Marcos Lopes AC, Campaner AB, Henrique LQ. Prevalence of high-grade intraepithelial neoplasia in patients with cytology presenting atypical squamous cells of undetermined significance. Acta Cytol 2016;60:139-44. [CrossRef]

9. Solomon D, Davey D, Kurman R, Moriarty A, O'Connor D, Prey M, et al. The 2001 bethesda system: Terminology for reporting results of cervical cytology. JAMA 2002;287:2114-9. [CrossRef]

10. Jemal A, Bray F, Center MM, Ferlay J, Ward E, Forman D, et al. Global cancer statistics. CA Cancer J Clin 2011;61:69-90. [CrossRef]

11. ASCUS-LSIL Traige Study (ALTS) Group. A randomized trial on the management of low-grade squamous intraepithelial lesion cytology interpretations. Am J Obstet Gynecol 2003;188:1393-400. [CrossRef]

12. National Cancer Institute. SEER Cancer Statistics Review, 1975-2009.
Available at: http://www.seer.cancer.gov/csr/ 1975_2009_pops09. Accessed May 31, 2016.

13. Stolnicu S, Musca S, Micu D, Micu L, Moldovan C, Puscasiu L, et al. Prevalence of abnormal pap smears in a consecutive and previously unscreened population in Romania. Int J Gynaecol Obstet 2014;124:156-9.

14. Turkish Cervical Cancer and Cervical Cytology Research Group. Prevalence of cervical cytological abnormalities in Turkey. Int J Gynaecol Obstet 2009;106:206-9. [CrossRef]

15. Bentley E, Cotton SC, Cruickshank ME, Duncan I, Gray NM, Jenkins $\mathrm{D}$, et al. Refining the management of low-grade cervical abnormalities in the UK national health service and defining the potential for human papillomavirus testing: A commentary on emerging evidence. J Low Genit Tract Dis 2006;10:26-38. [CrossRef]

16. Kabaca C, Sariibrahim B, Keleli I, Karateke A, Cesur S, Cetiner H, et al. The importance of immediate verification of a cervical cytological abnormality with histology. Indian J Cancer 2013;50:292-6. [CrossRef]

17. Skopljanac-Macina L, Mahovlić V, Ovanin-Rakić A, Barisić A, Rajhvajn $\mathrm{S}$, Juric D, et al. Cervix cancer screening in croatia within the European cervical cancer prevention week. Coll Antropol 2010;34:613-7.

18. Wright TC, Sun XW, Koulos J. Comparison of management algorithms for the evaluation of women with low-grade cytologic abnormalities. Obstet Gynecol 1995;85:202-10. [CrossRef]

19. Giorgi Rossi P, Ricciardi A, Cohet C, Palazzo F, Furnari G, Valle S, et al. Epidemiology and costs of cervical cancer screening and cervical dysplasia in Italy. BMC Public Health 2009;9:71. [CrossRef]

20. Pothisuwan M, Pataradool K, Tangjitgamol S, Srijaipracharoen S, Manusirivithaya $S$, Thawaramorn T, et al. Visual inspection with acetic acid for detection of high grade lesion in atypical squamous cells and low grade squamous intraepithelial lesions from cervical pap smear. J Gynecol Oncol 2011;22:145-51. [CrossRef] 